\title{
Recurrent aphthous stomatitis in 18-year-old adolescents - Prevalence and associated factors: a population-based study*
}

\author{
Paulo Ricardo Martins de Souza ${ }^{1,4}$ \\ Juliano de Avelar Breunig ${ }^{3}$
}

\author{
Rodrigo Pereira Duquia ${ }^{2}$ \\ Hiram Larangeira de Almeida JR ${ }^{4,5}$
}

DOI: http:/ / dx.doi.org/10.1590/abd1806-4841.20174692

\begin{abstract}
BACKGROUND: Recurrent aphthous stomatitis is a painful disorder of unknown etiology. It is among the most common oral mucosal lesions with high prevalence among young adults.

Овлестіvеs: To conduct a population-based study with 18-year-old army recruiters to assess its prevalence and associated factors in male adolescents.

METHODS: Interview during clinical examination in the army.

RESULTS: In this group (2,427 interviewed adolescents) there was a RAS prevalence of $24.9 \%$. Smoking, herpes labialis and socioeconomic status correlated with the outcome.

StUdy LimitaTions: only male adolescents were interviewed.

Conclusions: Our results showed high prevalence of RAS; association with higher economic level and herpes simplex was found. Protective effect of smoking was confirmed.
\end{abstract}

Keywords: Adolescent; Epidemiology; Stomatitis, Aphthous

\section{INTRODUCTION}

Recurrent aphthous stomatitis (RAS) is a painful disorder of unknown etiology. It is among the most common oral mucosal lesions, with clinically significant morbidity, and high prevalence among young adults. Subjects with RAS can present huge impact on their psychological and social well being. ${ }^{1}$

Population-based studies on RAS are scarce. Specific literature describes an increased risk of oral diseases among high socioeconomic class individuals. Furthermore, evidence suggests a weak correlation between RAS and recurrent herpes simplex labialis. ${ }^{2}$ Some previous studies suggested a protective effect of smoking on RAS..$^{3-4}$

Lack of epidemiological research on the topic in our country has encouraged us to conduct a population-based study to assess its prevalence and associated factors.

\section{METHODS}

This is a cross-sectional population-based study on the prevalence and factors associated with aphthae among 18-year-old male teenagers, living in the urban and rural areas of the city of Pelotas, who have joined the military service. In Brazil, military service is mandatory for all Brazilian men when they turn 18. Trained pro- fessionals applied a questionnaire to all young men who joined the military service. This questionnaire included questions about housing, smoking, skin color and some specific questions about mouth sores, herpes and oral health. The Brazilian classification for family income was used, A is the highest income and $\mathrm{E}$ the lowest. All participants were measured for weight, height and skin folds.

During the interview, the following statement was read: "I am going to ask you a few questions about aphthae. Aphthae are painful sores that appear inside the mouth usually on the inner lips, cheeks or tongue. They usually last from 7 to 14 days and heal even without treatment. Aphthae usually occur several times during our life, i.e. they are recurrent". Some photographs of aphthae were then showed to the respondents. Subsequently, the following questions were asked: "Have you ever had aphthae?". If the answer was "Yes", a second question was asked, "Have you ever had more than 3 episodes of aphthae a year?". Our outcome was characterized by this second affirmative answer. Reading the text about aphthae and showing some photographs were used to increase their sensitivity towards the survey questions.

\footnotetext{
Received on 04.05.2015.

Approved by the Advisory Board and accepted for publication on 25.06.2016.

Study conducted at the Programa de Pós-graduação em Saúde e Comportamento - Universidade Católica de Pelotas (UCPel) - Pelotas (RS), Brazil.

Financial support: None.

Conflict of interest: None.

Dermatology Service, Santa Casa de Misericórdia de Porto Alegre - Porto Alegre (RS), Brazil.

Department of Dermatology, Universidade Federal de Ciências da Saúde de Porto Alegre - Porto Alegre (RS), Brazil

Department of Dermatology, Universidade de Santa Cruz do Sul (UNISC) - Santa Cruz do Sul (RS), Brazil.

Post-Graduation Program in Health and Behavior, Universidade Católica de Pelotas (UCPEL)- Pelotas (RS), Brazil

Department of Dermatology, Universidade Federal de Pelotas (UFPel) - Pelotas (RS), Brazil.
} 
Individuals with mental disability or inability to respond the questionnaire were excluded.

Analyses were performed using Stata software. Adjusted and crude analyses were carried out using Poisson multiple regression, the variables were put in the same level, with the backward method, in order to evaluate the effect of each one independently. Variables with a p value lower than 0,2 were excluded. Significance level used was $5 \%$.

This study was approved by the Research Ethics Committee of the Santa Casa de Misericórdia of Pelotas. The confidentiality of the individual data will be guaranteed. The interviews were conducted only after the participants provided their free and informed consent.

\section{RESULTS}

A total of 2,427 adolescents were interviewed. Among these, 409 reported having more than three episodes of aphtae in the previous year, which showed a $24.9 \%$ prevalence of RAS.

Table 1 describes the sample and the prevalence of RAS according to the independent variables.

For the associated factors, smoking, history of herpes labialis and socioeconomic status correlated with the outcome (Table 2).

Smoking proved to be a protective effect on RAS in the previous year, with a prevalence rate of 0.59 (IC 95\% 0.43-0.81) in the

TABLE 1: Sample description with respective prevalence of RAS

\begin{tabular}{ccc} 
Variables & $\begin{array}{c}\text { Total } \\
\text { Sample (\%) }\end{array}$ & $\begin{array}{c}\text { Prevalence of } \\
\text { aphtae \% (IC) }\end{array}$ \\
\hline Smoking & $1.885(83.5)$ & $26.2(23.9-28.6)$ \\
\hline No & $372(16.5)$ & $15.5(11.3-20.7)$
\end{tabular}

Skin Color

$0.2^{*}$

White

$1.711(70.5) \quad 25.7(23.4-28.3)$

Non-White

$716(29.5)$

$22.5(18.7-26.8)$

With herpes labialis

$\begin{array}{lcc}\text { No } & 2.193(90.4) & 24.1(22.0-26.3) \\ \text { Yes } & 233(9.6) & 32.7(25.8-40.5)\end{array}$

Oral Health

Great/Fair

$1.371(56.6) \quad 24.1(21.5-26.9)$

Regular

$920(38.0)$

$26.2(22.8-29.9)$

Bad/Terrible

$131(5.4)$

$25.6(17.3-36.2)$

Triciptal folds

1st tercile

809 (33.4) $23.7(20.1-27.6)$

2nd tercile

$808(33.4) \quad 25.0(21.6-28.8)$

3rd tercile

$805(33.2)$

$25.8(22.4-29.5)$

Socioeconomic

status ABEP ***

$\begin{array}{ccl}\text { Level E/D } & 104(4.4) & 7.8(29.4-19.3) \\ \text { Level A/B/C } & 2.280(95.6) & 25.6(23.5-27.9)\end{array}$

$0.004^{*}$

${ }^{*}$ Chi square test ${ }^{* *}$ Linear tendency test ${ }^{* * *}$ Brazilian classification for family income

$0.4^{* *}$ crude analysis, and 0.62 (IC 95\% 0.46-0.85) after adjusting for all other independent variables.

For those individuals who reported having herpes labialis, the prevalence ratio was 1.36 (IC 95\% 1.07-1.73) and remained statistically significant in the adjusted analysis 1.53 (IC 95\%1.20-1.94). Among individuals with higher socioeconomic level, prevalence ratio of RAS was 3.27 (IC 95\% 1.27-8.41) in the crude analysis and 2.90 (IC 95\% 1.13-7.54) in the adjusted analysis.

The variables skin color, triciptal fold and oral health were not associated with the outcome.

TABLE 2: Crude and adjusted prevalence ratio for RAS

\begin{tabular}{|c|c|c|c|c|}
\hline Variables & $\begin{array}{c}\text { Crude } \\
\text { prevalence } \\
\text { ratio }\end{array}$ & $P$ value & $\begin{array}{c}\text { Adjusted } \\
\text { prevalence } \\
\text { ratio }\end{array}$ & $\begin{array}{c}P \\
\text { value }\end{array}$ \\
\hline Smoking & & $0.001^{*}$ & & $0.003^{*}$ \\
\hline No & 1.00 & & 1.00 & \\
\hline Yes & $\begin{array}{c}0.59 \\
(0.43-0.81)\end{array}$ & & $\begin{array}{c}0.62 \\
(0.46-0.85)\end{array}$ & \\
\hline Skin Color & & $0.2^{*}$ & & $0.5^{*}$ \\
\hline White & 1.00 & & 1.00 & \\
\hline Non-White & $\begin{array}{c}0.90 \\
(0.71-1.07)\end{array}$ & & $\begin{array}{c}0.93 \\
(0.76-1.15)\end{array}$ & \\
\hline With herpes & & $0.01^{*}$ & & $0.001^{*}$ \\
\hline
\end{tabular}

labialis

No

1.00

1.00

Yes

1.36

1.53

$(1.07-1.73)$

$(1.20-1.94)$

\begin{tabular}{|c|c|c|}
\hline Oral Health & & \\
\hline Great/Fair & 1.00 & 1.00 \\
\hline Regular & $\begin{array}{c}1.09 \\
(0.91-1.30)\end{array}$ & $\begin{array}{c}1.09 \\
(0.90-1.31)\end{array}$ \\
\hline Bad/Terrible & $\begin{array}{c}1.06 \\
(0.72-1.56)\end{array}$ & $\begin{array}{c}1.05 \\
(0.68-1.61)\end{array}$ \\
\hline
\end{tabular}

\section{Triciptal}

folds

1st tercile

$0.4^{* *}$

$0.7^{* *}$

2nd tercile

1.00

1.00

1.06

0.99

3rd tercile

(0.85 - 1.31)

$(0.79-1.24)$

1.09

1.04

(0.86 - 1.34)

(0.84 - 1.30)

Socioeco-

nomic status

$0.01^{*}$

$0.03 *$

$\begin{array}{ccc}\text { Level E/D } & 1.00 & 1.00 \\ \text { Level A/C } & 3.27 & 2.91 \\ & (1.27-8.41) & (1.13-7.54)\end{array}$

* Wald Test for heterogeneity ** Wald test for linear trend *** Brazilian classification for family income 


\section{DISCUSSION}

Recurrent aphthous stomatitis (RAS) comprises recurrent painful oral ulcers at intervals of a few months to a few days. This common disorder is observed worldwide, rarely associated with systemic disease. ${ }^{5}$

Our prevalence data are comparable to those found in literature, which are mostly self-reported. The point prevalence based on clinical examination was reported in most studies; however, it did not reveal the actual data related to this recurrent disease.

The reported prevalence of RAS has varied significantly depending on the method used and the study population. In Turkey, the prevalence was $22.8 \%$ (11,360 respondents); in Iran, $25.2 \%$ (10,291 respondents); and in Jordan, $37.3 \%$ (2,175 respondents). ${ }^{6-8}$

A study by Axell (1976), where he conducted oral examination on 22,033 participants, reported the prevalence of oral mucosal lesions in adult Swedish population. ${ }^{9}$ The clinical criteria for aphtae were: well-demarcated ulcers of the non-keratinized mucosa, ulcers painful to palpation and reports of recurrence in the last 2 years. During the study period, the point prevalence of RAS was $2 \%$. In this same study sample, $17.7 \%$ subjects informed to have RAS in the last 2 years, prevalence very similar to that found in our study, which emphasizes the importance of self-reports, considering that only a few subjects would present lesions during examination.

For the associated factors, our findings are in agreement with the association with higher economic level, which was reported by the Turkish population and also in a study conducted in Argentina. ${ }^{6,10}$ In a study with baseball players in Arizona, lower prevalence has been identified in African-American individuals, also in accordance with our data. ${ }^{11}$

Association with smoking with protective effect has been confirmed by several studies (Turkey, Sweden, Arizona), in accordance with our findings. ${ }^{6-9,11}$

Sawair studied the association between smoking and RAS with 1,000 students of the University of Jordan. ${ }^{12}$ Details of smoking history and RAS were obtained from each student. Annual prevalence of RAS was 37.1\% (371 students had RAS in the previous year). Prevalence was significantly affected by the number of cigarettes smoked. Heavy smokers had one-third the odds of RAS than light smokers. In addition, cigarette smokers for periods more than five years had one-third the odds of RAS than those who smoked less than 5 years.

Marakoglu et al. conducted a study to evaluate the frequency of recurrent aphthous stomatitis (RAS) in individuals who were quitting smoking. ${ }^{3}$ The study group consisted of 90 subjects who answered a questionnaire that included information on age, previous diseases, smoking habits and frequency of aphthous ulcer. Nicotine replacement therapy (NRT) was applied to some of the subjects considering the Fagerstrom Test for Nicotine Dependence level. In this 6-week cessation program, 64 of the 90 smokers quit smoking. RAS prevalence on the first day of the quitting period was $3.3 \%$. After a week, 17 (26.5\%) had ulcers. At the end of the third week, 19 had ulcers $(31.6 \%)$. As the time after quitting increased, incidence of aphthous ulcer decreased. A possible explanation would be that smoking increases keratinization of the oral mucosa, and consequently, the susceptibility to ulceration.

Few studies have evaluated the association between RAS and herpes labialis. Katz et al. conducted a study with 20,689 soldiers (14,991 men and 5,698 women), aged between 18 and 21 years. ${ }^{2}$ RAS prevalence was $6.2 \%$ (self-reported) and herpes labialis was $5.4 \%$. RAS appeared more frequently in women than men. Presence of RAS among those diagnosed with herpes labialis was 6.88 times higher compared with those with a negative diagnosis (women). Among men, RAS was 12.37 times higher among those with positive herpes labialis. Prevalence of RAS and herpes was one of the lowest ever reported. This may be due the fact soldiers tend to complain less than the general population, and also because they constitute a more homogeneous population in age and medical condition. Our findings also showed an association with past history of herpes labialis.

\section{CONCLUSION}

Our results showed high prevalence of RAS in this young population, with association with higher economic level and history of herpes simplex. The protective effect of smoking was confirmed by our findings. 


\section{REFERENCES}

1. Chattopadhyay A, Chatterjee S. Risk indicators for recurrent aphthous ulcers among adults in the US. Community Dent Oral Epidemiol. 2007;35:152-9.

2. Katz J, Chaushu G, Peretz B.Recurrent oral ulcerations associated with recurrent herpes labialis--two distinct entities? Community Dent Oral Epidemiol. 2001;29:260-3.

3. Marakoğlu K, Sezer RE, Toker HC, Marakoğlu I. The recurrent aphthous stomatitis frequency in the smoking cessation people. Clin Oral Investig. 2007;11:149-53.

4. Ussher M, West R, Steptoe A, McEwen A. Increase in common cold symptoms and mouth ulcers following smoking cessation. Tob Control. 2003;12:86-8.

5. Bittencourt Mde J, Dias CM, Lage TL, Barros RS, Paz OA, Vieira Wde B. Beçhet syndrome in association with Budd-Chiari syndrome and multiple thrombosis Case report. An Bras Dermatol. 2013;88:448-51.

6. Ciçek Y, Canakçi V, Ozgöz M, Ertas U, Canakçi E. Prevalence and handedness correlates of recurrent aphthous stomatitis in the Turkish population. J Public Health Dent. 2004;64:151-6.

7. Davatchi F, Tehrani-Banihashemi A, Jamshidi AR, Chams-Davatchi C, Gholami J, Moradi M, et al. The prevalence of oral aphthosis in a normal population in Iran: a WHO-ILAR COPCORD study. Arch Iran Med. 2008;11:207-9.

8. Darwazeh AM, Pillai K. Oral lesions in a Jordanian population. Int Dent J. 1998:48:84-8.

9. Axéll T, Henricsson V. The occurrence of recurrent aphthous ulcers in an adult Swedish population. Acta Odontol Scand. 1985;43:121-5.

10. Borghelli RF, Gaig DH, Policicchio J, Centofanti MH, Gaffner M. Aftas bucales: Prevalencia, historia y nivel socioeconómico en poblaciones seleccionadas de Argentina. Rev Asoc Odont Argen. 1985;73:12-4.

11. Grady D, Ernster VL, Stillman L, Greenspan J. Smokeless tobacco use prevents aphthous stomatitis. Oral Surg Oral Med Oral Pathol. 1992;74:463-5.

12. Sawair FA. Does smoking really protect from recurrent aphthous stomatitis? Ther Clin Risk Manag. 2010;6:573-7.
MAILING ADDRESS:

Hiram Larangeira de Almeida Jr

Gonçalves Chaves, 373

96015-560 - Pelotas, RS

Brazil

Email:hiramalmeidajr@hotmail.com

How to cite this article: Marins de Souza PR, Duquia RP, Breunig JA, Almeida HL Jr. Recurrent aphthous stomatitis in 18-year-old adolescents - Prevalence and associated factors: a population-based study. An Bras Dermatol. 2017;92(5):626-9. 